\title{
Strategi Pengembangan Model Bisnis Zavair Scraves dengan menggunakan pendekatan BCG Matrix
}

\author{
Herlina Sari ${ }^{1}$, Mokh. Adib Sultan ${ }^{2}$ \\ Program Studi Manajemen, Sekola Pascasarjana, Universitas Pendidikan Indonesia, Bandung, Indonesia ${ }^{1}$ \\ Program Studi Manajemen, FPEB, Universitas Pendidikan Indonesia, Bandung, Indonesia²
}

\begin{abstract}
Sales and offers of an item or service have switched through social media. The transition of this business trend makes business competition in Indonesia even tighter, both in sales online and offline. This business trend also has an impact on the hijab fashion industry, making Zavair scarves in red ocean strategy. This study aims to identify the weaknesses, strengths, threats and opportunities of Zavair scarves, and find and recommend the right strategies to help Zavair scarves develop his business and products. To collect data, the author uses interviewing techniques for the owner of Zavair scarves, which is then analyzed using a SWOT analysis, then weighting internal and external factors. Data is processed using IFE and EFE. The next step is to determine the TOWS Matrix. And the last stage is using BCG Matrix. The results showed that Zavair scarves was in quadrant I in the IE Matrix and was in quadrant II of the BCG Matrix.
\end{abstract}

Keywords. analisis swot; boston consulting group; business model

Abstrak. Penjualan dan penawaran suatu barang atau jasa sudah beralih melalui media sosial. Adanya peralihan trend bisnis ini membuat persaingan bisnis di Indonesia semakin ketat, baik dalam penjualan online maupun offline. Trend bisnis ini juga berdampak pada industry fashion hijab, menjadikan Zavair scarves berada dalam red ocean strategy. Penelitian ini bertujuan untuk mengidentifikasi kelemahan, kekuatan, ancaman dan peluang Zavair scarves, serta menemukan dan merekomedasikan strategi yang tepat untuk membantu Zavair scarves dalam mengambangkan bisnisnya dan produknya. Untuk mengumpulkan data, penulis menggunakan teknik wawancara terhadap owner Zavair scarves yang kemudian di analisis menggunakan analisis SWOT, selanjutnya dilakukan pembobotan factor internal dan external. Data diolah menggunakan IFE dan EFE. Tahap selanjutnya yaitu menentukan TOWS Matrix. Dan tahapan terakhir menggunakan BCG Matrix. Hasil penelitian menunjukkan Zavair scarves berada pada kuadran I pada IE Matrix dan berada pada kuadran II pada BCG Matrix.

Kata Kunci. analisis swot; boston consulting group; business model

Correspondence. herlinasari@upi.edu

History of article. Received: April 2019, Revision: Juli 2019, Published: September 2019

\section{PENDAHULUAN}

Trend bisnis online berdampak pada industry fashion di Indonesia. Termasuk dalam industry fashion di Kota Bandung. Seperti yang kita ketahui Kota Bandung merupakan salah satu kota terbesar di Indonesia yang terkenal dengan perkembangan fashionnya, bahkan Kota Bandung di juluki dengan nama Paris Van Java. Fashion di Bandung sering dijadikan trendsetter oleh masyarakat di Indonesia. Hal ini terlihat dari banyaknya fashion Designer yang berasal dari Kota Bandung dan adanya beberapa kursus dalam bidang fashion. Trends fashion saat ini juga bukan hanya sekedar baju tapi juga merambah dunia hijab. Mayoritas penduduk Indonesia memeluk agama islam, saat ini Trend fashion hijab sangat diminati oleh masyarakat. Adanya trend fashion hijab ini, membuat para penjual online shop di Kota Bandung berada dalam persaingan yang ketat. Terlebih saat ini trend fashion hijab sudah mendunia. Banyak fashion Designer hijab yang bermunculan di Indonesia bahkan fashion Designer ini terkenal di luar negeri. Selain itu banyak juga event-event yang mengadakan fashion show khusus untuk hijab. Dari fenomena ini banyak orang berlomba-lomba untuk merambah ke fashion hijab.

Bisnis hijab sangat menjanjikan di Negara Indonesia saat ini maupun beberapa tahun kedepan. Melihat peluang ini, Zavair Scarves merupakan salah satu online shop yang berasal dari Kota Bandung merambah bisnis di bidang fashion hijab. Dengan banyaknya online shop yang bergerak di bidang Fashion Hijab yang ada di Indonesia, menjadikan Zavair scarves berada dalam red ocean strategy. Hal ini mengharuskan Zavair scarves untuk lebih memperhatikan apa saja yang terus membuat online 
shop bertahan, tumbuh dan berkembang, dalam hal ini online shop semakin dituntut agar bergerak lebih cepat dalam hal menarik konsumen. Online shop juga dituntut untuk lebih kreatif dan inovatif agar terus bisa bersaing dalam pasar.

Beberapa Penelitian terdahulu dengan menggunakan BCG Matriks. Suranto \& Yulianto (2003) berdasarkan analisis BCG Matrik, perusahaan Firma Sidodadi berada pada kuadran Dogs dimana pangsa pasar produk rendah dan pertumbuhan pasar rendah. Nurhanasah N (2006) berdasarkan analisis BCG matrik bahwa perusahaan berada pada posisi tanda Tanya. Sebanyak 3 strategi yang terpilih melalui Trapezoidal Fuzzy Number yaitu menambah pasar baru melalui pengembangan produk baru, bermitra dalam investasi dan menerobos pasar yang ada. Torlak and Sanal (2007) penelitian ini menggunakan kerangka rumusan Fred David studi kasus pada Turkish Airline yang menerapkan kerangka strategi David untuk mengoperasikan perusahaannya dan penelitian ini merekomendasikan strategi yang tepat untuk perusahaan Turkish Airline dalam proses manajemen strategi. Kuntjoroardi, Safitri (2009) hasil penelitian ini menunjukkan posisi bersaing Garuda berada pada posisi "star" yang berarti bahwa Garuda memiliki pertumbuhan long-run opportunites yaitu Garuda akan memiliki pangsa pasar yang relative tinggi.

Sarjono \& Kuncoro (2013) berdasarkan analisis matriks BCG, didapatkan bahwa Sekolah Tinggi untuk tahun ajaran 2008-2009 berada pada kuadran III (cash cow) karena memiliki posisi pangsa pasar relative yang rendah. Akan tetapi dapat bersaing dalam industry yang bertumbuh pesat. Cash cow berarti bahwa perusahaan dapat melanjutkan bisnis yang sedang dijalankan akan tetapi bergantung pada kondisi keuangan yang ada. Poniran (2013) berdasarkan matrik BCG posisi dari masing-masing SBU PT Gudang Garam Tbk menunjukkan kegiatan bisnis SKM, SKT dan SKL masuk dalam kelompok "cash cows", dimana tingkat pertumbuhan pasarnya rendah, sedang pangsa pasarnya tinggi, yang artinya bahwa product SKM, SKT dan SKL tumpuan dari kegiatan usaha tersebut, akrena aliran kas yang besar hanya didapatkan dari kegiatan bisnis ini.

Savitri, Sumarwan, Kurniawan (2014) hasil Tingkat pertumbuhan pasar dan bagian pasar relatifnya yang di formulasikan pada diagram BCG berada pada posisi Question Marks artinya bisnis ini memiliki peluang untuk tumbuh dan berkembang tetapi diperlukan aliran kas yang cukup agar dapat meningkatkan pasar relatifnya. Barusman (2014) hasil penelitian menunjukkan bahwa kesebelas produk PT. Asuransi Umum Bumiputeramuda 1967 cabang Lampung menempati kuadran berbeda-beda yaitu 1) pada kuadran I atau Question Mark terdapat enam produk yang dipetakan dalam posisi ini. 2) pada kuadran II atau star, terdapat empat produk asuransi.

Winardi (2014) hasil penelitian tersebut berupa strategi operasional Bisnis Konsultan yaitu melakukan penetrasi pasar, pengembangan jasa konsultasi, penciutan biaya dan usaha patungan.

Hardiyansyah, Ikhwana, Kurniawati (2015) hasil penelitian ini menunjukkan bahwa posisi PD. Lugina berada pada kuadran I, yang artinya posisi perusahaan berada dalam kondisi pangsa pasar yang rendah tetapi dengan pertumbuhan industry sangat tinggi. Penelitian Maulana, Sukamdani, Sulistyadi (2016) hasil penelitian menunjukkan bahwa ada 2 pulau pada destinasi Kepulauan Seribu yang berada di kuadran cash cows, ada 2 pulau yang masuk kuadran question mark, da nada 36 pulau yang masuk kuadran dogs.

Isnandar, Firdaus, Maulana (2016) berdasarkan analisis matrik BCG, BPRS HIK Ciledug berada pada kuadran II atau stars dengan posisi pangsa pasar terbilang tinggi. Perusahaan yang berada di kuadran II pada matriks BCG memiliki produk yang memimpin di pasar/industry, akan tetapi masih membutuhkan dukungan serta harus meningkatkan promosi di masa depan. Guntara, Yogaswara, Aurachman (2017) hasil penelitian menunjukkan bahwa terdapat 19 faktor lingkungan eksternal dan 15 faktor lingkungan internal yang memperngaruhi strategi perusahaan, posisi bisnis perusahaan ini berada pada kuadran Question Marks.

Berdasarkan penelitian terdahulu, melakukan strategi pengembangan model bisnis atau melakukan analisis model bisnis untuk mengetahui posisi perusahaan dengan menggunakan pendekatan Matriks BCG sangat diperlukan untuk perkembangan suatu perusahaan. Setelah suatu perusahaan mengetahui posisi perusahaan, perusahaan bisa mengambil langkah yang tepat untuk memajukan perusahaan. Berdasarkan fenomena dan penelitian terdahulu,

Penelitian ini bertujuan untuk mengembangkan bisnis model untuk online shop Zavair scraves dengan menggunakan BCG Matrix untuk melihat bagaimana model bisnis yang sedang dijalani. Melalui BCG Matrix, Zavair scraves akan melihat dimana posisi perusahaan mereka berada. Selain itu penelitian ini juga akan menganalisa mengunakan metode analisa SWOT. Jadi penelitian ini akan menggabungkan antara BCG Matrix dan analisa SWOT untuk menciptakan strategi pengembangan bisnis yang sesuai dengan prioritas kebutuhan perusahaan dan menyesuaikan dengan kondisi pasar saat ini. Diharapkan perusahaan mengetahui apa yang menjadi kelemahan, keunggulan, peluang dan ancaman bagi perusahaan agar perusahaan mendapatkan strategi terbaik untuk 
pengembangan bisnis mereka. Sehingga, perusahaan dapat bertahan dan dapat meningkatkan penjualan dengan maksimal serta sehingga perusahaan dapat berkembang dengan cepat.

\section{KERANGKA PENELITIAN \& HIPOTESIS}

Kewirausahaan adalah suatu disiplin ilmu yang mempelajari tentang nilai, kemampuan (ability), dan prilaku seseorang dalam menghadapi tantangan hidup dan cara memperoleh peluang dengan berbagai resiko yang mungkin dihadapinya. Kewirausahaan merupakan suatu disiplin ilmu tersendiri, memiliki proses sistematis, dan dapat diterapkan dalam bentuk penerapan kreativitas dan keinovasian. Seperti yang dikemukakan Thomas W. Zimmerer (1996), "entrepreneurship is the result of disciplined, systematic process of applying creativity and innovations to needs and opportunities in the marketplace". Kewirausahaan merupakan hasil dari suatu disiplin, proses sistematis penerapan kreativitas dan inovasi dalam memenuhi kebutuhan dan peluang di pasar. (Suryana, 2014)

Pengertian wirausaha lebih lengkap dinyatakan oleh Joseph Schumpeter dalam Buchari Alma (2018:24) mengemukakan bahwa Entrepreneur as the person who destroys the exixting economic order by introducing new products and services, by creating new forms of organization, or by exploiting new raw materials. Dimana dijelaskan bahwa wirausaha adalah orang yang mendobrak sistem ekonomi yang ada dengan memperkenalkan barang dan jasa yang baru, dengan menciptkan bentuk organisasi baru atau mengolah bahan baku baru).

Gassman et al. (2016) mengemukakan bahwa model bisnis bukan merupakan suatu struktur yang terpisah, tetapi merupakan jaringan hubungan yang rumit dan mandiri dengan lingkungan bisnis yang senantiasa berubah. Seorang pelaku bisnis harus dapat memperhatikan perubahan yang terjadi di lingkungan. Osterwalder dan Pigneur (2018) mengemukakan bahwa sebuah model bisnis menggambarkan dasar pemikiran tentang bagaimana organisasi menciptakan, memberikan, dan menangkap nilai. Konsep dasar sebuah model bisnis harus dilakukan secara sederhana, relevan dan secara intuitif dapat dipahami, tetapi tidak terlalu menyederhanakan kerumitan tentang bagaimana suatu usaha berfungsi.

Analisis matriks BCG dipergunakan untuk mengetahui posisi suatu perusahaan terhadap pesaingnya. Amstrong dan Brodie (1994) menyatakan, "The BCG matrix measures market attractiveness by market growth rate, and it assesses the firm's ability to compete by. Its relative market share. The BCG matrix assumes a causal relationship between market share and profitability". Day (1984) menyatakan, "Market attractiveness represents the long-run profit and growth potential for all participants in an industry or market, while competitive position relates to the strength of the organization relative to competition.

Kategori BCG (David, 2006): Question Mark adalah Divisi dalam kuadran I, memiliki posisi pangsa pasar relatif rendah, tetapi mereka bersaing dalam industri yang bertumbuh pesat. Biasanya kebutuhan kas perusahaan ini tinggi dan pendapatan kasnya rendah. Bisnis ini disebut tanda tanya karena organisasi harus memutuskan apakah akan memperkuat divisi ini dengan menjalankan strategi intensif (penetrasi pasar, pengembangan pasar, atau pengembangan produk) atau menjualnya.

Star adalah Bisnis di kuadran II, mewakili peluang jangka panjang terbaik untuk pertumbuhan dan profitabilitas bagi organisasi. Divisi dengan pangsa pasar relatif yang tinggi dan tingkat pertumbuhan industri yang tinggi seharusnya menerima investasi yang besar untuk mempertahankan atau memperkuat posisi dominan mereka. Integrasi ke depan, ke belakang, dan horizontal; penetrasi pasar, pengembangan pasar; pengembangan produk dan joint venture adalah strategi yang sesuai untuk dipertimbangkan divisi ini.

Cash Cow adalah Divisi yang berpotensi di kuadran III, memiliki pangsa pasar relatif yang tinggi bersaing tetapi bersaing dalam industry yang pertumbuhannya lambat. Disebut Sapi perah karena mereka menghasilkan kas lebih dari yang dibutuhkannya, mereka sering kali diperah. Banyak sapi perah saat ini adalah bintang di masa lalu. Divisi sapi perah harus dikelola untuk mempertahankan posisi kuatnya selama mungkin, Pengembangan produk atau diversifikasi konsentris dapat menjadi strategi yang menarik untuk sapi perah yang kuat, tetapi ketika divisi sapi perah menjadi lemah, retrenchment atau diverstasi lebih sesuai untuk diterapkan.

Dog adalah Divisi kuadran IV dari organisasi memiliki pangsa pasar relatif yang rendah dan bersaing dalam industri yang pertumbuhannya rendah atau tidak tumbuh; mereka adalah Anjing dalam portofolio perusahaan. Karena posisi internal dan eksternalnya lemah, bisnis ini sering kali dilikuidasi, divestasi atau dipangkas dengan retrenchment. Ketika sebuah divisi menjadi anjing, retrenchment dapat menjadi strategi terbaik yang dapat dijalankan karena banyak anjing yang mencuat kembali, setelah pemangkasan biaya dan asset besar-besaran, menjadi bisnis yang mampu bertahan dan menguntungkan. 


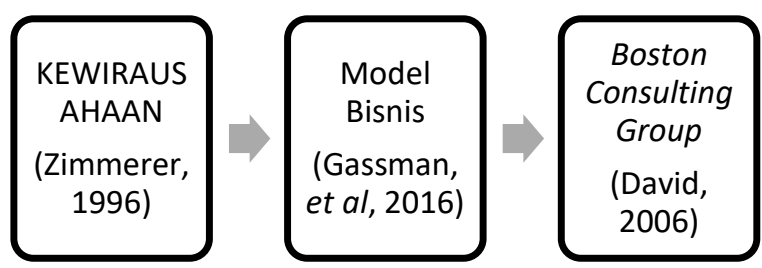

GAMBAR 1.1 KERANGKA PEMIKIRAN

\section{METODE PENELITIAN}

Jenis penelitian yang digunakan adalah penelitian kualitatif deskriptif, dimana penelitian ini berupaya mengumpulkan data, menganalisis secara kritis atas data-data tersebut dan menyimpulkannya berdasarkan fakta-fakta pada masa penelitian (Sugiama, 2008). Pengumpulan data dilakukan dengan cara mengidentifikasi kekuatan, kelemahan, peluang dan ancaman perusahaan atau yang disebut analisis SWOT. Selanjutnya dilakukan pembobotan factor internal dan ekternal. Data diolah menggunakan Matrix internal factor evaluation (IFE) dan Matrix External Factor Evaluation (EFE). Setelah diketahui skor disetiap masing-masing factor pada Matrix IFE dan Matrix EFE maka akan diketahui weighted score. Weighted score tersebut digunakan untuk melihat posisi dari perusahaan pada kuadran IE Matrix. Tahap selanjutnya yaitu menentukan TOWS Matrix, Empat strategi utama yang dirumuskan yaitu, strategi SO (strength dan opportunities), strategi WO (weakness dan opportunities), strategi ST (strength dan threats) dan strategi WT (weakness dan threats). Tahapan selanjutnya adalah menentukan prioritas yang akan dijalankan perusahaan dengan mengunakan BCG (Boston Consulting Group) Matrix.

Data yang digunakan dalam penyusunan penelitian ini berupa data primer yang langsung didapat dari sumber, dalam hal ini sumber penelitian ini adalah owner dan pegawai dan data sekunder didapat dari data yang lebih dulu dikumpulkan dan dilaporkan oleh orang lain. Sumber data sekunder antara lain dari penelitian terdahulu, brosur-brosur, buku atau dokumen, internet. Metode pengumpulan data dalam penelitian ini menggunakan teknik Observasi, Studi kepustakan, Wawancara. Metode analisis data untuk tujuan penelitian ini adalah dengan menggunakan Matrik Boston Consulting Group (BCG).

\section{HASIL DAN PEMBAHASAN}

Hasil dari indentifikasi faktor internal dan faktor eksternal serta hasil pembobotan yang telah didapatkan melalui wawancara kepada pihak perusahaan memberikan rangkuman kekuatan, kelemahan, peluang dan ancaman dalam matrix IFE dan EFE pada Tabel dibawah ini. Setelah melakukan pembobotan dengan IFE dan EFE, maka diketahui weigthed score. Weigthed score tersebut digunakan untuk melihat posisi dari Zavair scarves pada kuadran IE Matrix serta untuk menentukan rekomendasi yang tepat untuk dijalankan oleh Zavair scarves.

TABEL 1.1 IFAS - STRENGHT

\begin{tabular}{|c|c|c|c|c|}
\hline No & Faktor & Bobot & Rank & Skor \\
\hline 1 & $\begin{array}{l}\text { Harga jual yang } \\
\text { murah }\end{array}$ & 0,04 & 5 & 0,2 \\
\hline 2 & $\begin{array}{c}\text { Packaging yang } \\
\text { menarik }\end{array}$ & 0,05 & 5 & 0,25 \\
\hline 3 & $\begin{array}{l}\text { Kualitas produk yang } \\
\text { terjamin }\end{array}$ & 0,05 & 5 & 0,25 \\
\hline 4 & $\begin{array}{l}\text { Produk yang terus di } \\
\text { update }\end{array}$ & 0,04 & 4 & 0,16 \\
\hline 5 & $\begin{array}{l}\text { Display Produk yang } \\
\text { menarik }\end{array}$ & 0,04 & 4 & 0,16 \\
\hline 6 & Melakukan giveaway & 0,04 & 4 & 0,16 \\
\hline 7 & $\begin{array}{l}\text { Memberikan harga } \\
\text { promo }\end{array}$ & 0,04 & 4 & 0,16 \\
\hline 8 & $\begin{array}{c}\text { Memberikan paket } \\
\text { Hemat }\end{array}$ & 0,04 & 4 & 0,16 \\
\hline 9 & $\begin{array}{l}\text { Memberikan kartu } \\
\text { ucapan sebagai } \\
\text { bentuk terima kasih } \\
\text { kepada konsumen }\end{array}$ & 0,04 & 4 & 0,16 \\
\hline 10 & $\begin{array}{l}\text { Pelayanan yang baik } \\
\text { dan ramah }\end{array}$ & 0,04 & 5 & 0,2 \\
\hline 11 & $\begin{array}{l}\text { Memiliki model } \\
\text { produk yang unik }\end{array}$ & 0,04 & 4 & 0,16 \\
\hline \multirow[t]{2}{*}{12} & $\begin{array}{l}\text { Produk bisa diterima } \\
\text { di semua kalangan }\end{array}$ & 0,04 & 5 & 0,25 \\
\hline & TOTAL & 0,5 & & 2.43 \\
\hline
\end{tabular}

Sumber: data diolah peneliti (2018)

TABEL 1.2 IFAS - WEAKNESS

\begin{tabular}{lllll}
\hline No & \multicolumn{1}{c}{ Faktor } & Bobot & Rank & Skor \\
\hline 1 & $\begin{array}{l}\text { Belum ada toko } \\
\text { offline }\end{array}$ & 0,03 & 2 & 0,06 \\
2 & $\begin{array}{l}\text { Tidak ada gudang } \\
3\end{array}$ & 0,03 & 2 & 0,06 \\
& $\begin{array}{l}\text { Pelayanan yang } \\
\text { kurang cepat }\end{array}$ & 0,02 & 1 & 0,02 \\
4 & $\begin{array}{l}\text { Jaringan yang belum } \\
\text { luas }\end{array}$ & 0,03 & 1 & 0,03 \\
5 & $\begin{array}{l}\text { Brand belum } \\
\text { terkenal }\end{array}$ & 0,02 & 1 & 0,02 \\
6 & $\begin{array}{l}\text { Biaya produksi yang } \\
\text { terbatas }\end{array}$ & 0,02 & 1 & 0,02
\end{tabular}




\begin{tabular}{|c|c|c|c|c|}
\hline 7 & $\begin{array}{l}\text { Produk gagal krn } \\
\text { Jahitan yang kurang } \\
\text { rapi }\end{array}$ & 0,02 & 1 & 0,02 \\
\hline 8 & $\begin{array}{l}\text { Manajemen waktu } \\
\text { karyawan yang masih } \\
\text { belum baik }\end{array}$ & 0,03 & 1 & 0,03 \\
\hline 9 & $\begin{array}{l}\text { Tidak ada laporan } \\
\text { keuangan }\end{array}$ & 0,03 & 2 & 0,06 \\
\hline 10 & $\begin{array}{l}\text { Komunikasi yang } \\
\text { kurang baik dengan } \\
\text { penjahit atau } \\
\text { konveksi }\end{array}$ & 0,03 & 1 & 0,03 \\
\hline 11 & $\begin{array}{l}\text { Tingkat kepercayaan } \\
\text { konsumen yang } \\
\text { masih rendah }\end{array}$ & 0,03 & 1 & 0,03 \\
\hline 12 & $\begin{array}{l}\text { Proses produksi yang } \\
\text { memakan waktu } \\
\text { cukup lama }\end{array}$ & 0,03 & 1 & 0,03 \\
\hline 13 & $\begin{array}{l}\text { Website belum } \\
\text { dikelola dengan baik }\end{array}$ & 0,03 & 1 & 0,03 \\
\hline 14 & $\begin{array}{l}\text { Variasi model produk } \\
\text { yang masih sedikit }\end{array}$ & 0,03 & 1 & 0,03 \\
\hline 15 & $\begin{array}{l}\text { Pemasaran yang } \\
\text { belum maksimal }\end{array}$ & 0,03 & 1 & 0,03 \\
\hline 16 & $\begin{array}{l}\text { Konsumen yang } \\
\text { masih seputaran } \\
\text { jawa barat }\end{array}$ & 0,03 & 1 & 0,03 \\
\hline 17 & $\begin{array}{l}\text { Jumlah pesanan } \\
\text { masih belum banyak }\end{array}$ & 0,03 & 1 & 0,03 \\
\hline 18 & $\begin{array}{l}\text { Struktur organisasi } \\
\text { masih sederhana }\end{array}$ & 0,03 & 1 & 0,03 \\
\hline & Total & & & 0,59 \\
\hline
\end{tabular}

Sumber: data diolah peneliti (2018)

\section{TABEL 1.3 EFAS - OPPORTUNITY}

\begin{tabular}{lllll}
\hline No & \multicolumn{1}{c}{ Faktor } & Bobot & Rank & Skor \\
\hline 1 & $\begin{array}{l}\text { Indonesia dengan } \\
\text { penduduk muslim } \\
\text { terbesar }\end{array}$ & 0,05 & 5 & 0,25 \\
2 & $\begin{array}{l}\text { Daya beli masyarakat } \\
\text { yang tinggi }\end{array}$ & 0,05 & 5 & 0,25 \\
$3 \quad \begin{array}{l}\text { Perkembangan trend } \\
\text { hijab }\end{array}$ & 0,05 & 5 & 0,25 \\
$4 \quad \begin{array}{l}\text { Permintaan pasar } \\
\text { yang besar }\end{array}$ & 0,05 & 5 & 0,25 \\
5 & $\begin{array}{l}\text { Banyaknya event- } \\
\text { event yang diadakan }\end{array}$ & 0,05 & 5 & 0,25 \\
6 & $\begin{array}{l}\text { Perkembangan } \\
\text { teknologi }\end{array}$ & 0,05 & 5 & 0,25 \\
& $\begin{array}{l}\text { E-commerce yang } \\
\text { sedang berkembang } \\
\text { pesat }\end{array}$ & 0,05 & 5 & 0,25
\end{tabular}

\begin{tabular}{|c|c|c|c|c|}
\hline 8 & $\begin{array}{l}\text { Banyaknya wanita } \\
\text { yang sudah memakai } \\
\text { hijab }\end{array}$ & 0,05 & 5 & 0,25 \\
\hline 9 & $\begin{array}{l}\text { Adanya dukungan } \\
\text { pemerintah untuk } \\
\text { UMKM atau industri } \\
\text { kreatif }\end{array}$ & 0,05 & 5 & 0,25 \\
\hline 10 & $\begin{array}{l}\text { Prospek yang cukup } \\
\text { menjanjikan }\end{array}$ & 0,05 & 5 & 0,25 \\
\hline & Total & 0,5 & & 2,5 \\
\hline
\end{tabular}

Sumber: data diolah peneliti (2018)

TABEL 1.4 EFAS - THREAT

\begin{tabular}{|c|c|c|c|c|}
\hline No & Faktor & Bobot & Rank & Skor \\
\hline 1 & $\begin{array}{l}\text { Harga bahan baku } \\
\text { yang naik }\end{array}$ & 0,02 & 1 & 0,02 \\
\hline 2 & $\begin{array}{l}\text { Biaya produksi yang } \\
\text { naik }\end{array}$ & 0,03 & 1 & 0,03 \\
\hline 3 & $\begin{array}{l}\text { Adanya plagiarisme } \\
\text { dalam model/design } \\
\text { produk }\end{array}$ & 0,02 & 1 & 0,02 \\
\hline 4 & $\begin{array}{l}\text { Konsumen tidak } \\
\text { sabar ketika balasan } \\
\text { order lama }\end{array}$ & 0,03 & 2 & 0,06 \\
\hline 5 & $\begin{array}{l}\text { Waktu pengiriman } \\
\text { yang lama }\end{array}$ & 0,03 & 2 & 0,06 \\
\hline 6 & $\begin{array}{l}\text { Jaringan yang belum } \\
\text { luas }\end{array}$ & 0,03 & 2 & 0,06 \\
\hline 7 & Persaingan harga & 0,03 & 2 & 0,06 \\
\hline 8 & $\begin{array}{l}\text { Tingkat kepercayaan } \\
\text { konsumen yang } \\
\text { masih rendah }\end{array}$ & 0,02 & 1 & 0,02 \\
\hline 9 & $\begin{array}{l}\text { Penipuan dengan } \\
\text { melakukan hit and } \\
\text { run }\end{array}$ & 0,01 & 1 & 0,01 \\
\hline 10 & Pesaing yang banyak & 0,01 & 2 & 0,02 \\
\hline 11 & $\begin{array}{l}\text { Pertumbuhan } \\
\text { ekonomi yang tidak } \\
\text { stabil }\end{array}$ & 0,02 & 2 & 0,04 \\
\hline 12 & $\begin{array}{l}\text { Inovasi produk } \\
\text { pesaing }\end{array}$ & 0,02 & 2 & 0,04 \\
\hline 13 & $\begin{array}{l}\text { Biaya pengiriman } \\
\text { naik }\end{array}$ & 0,02 & 2 & 0,04 \\
\hline 14 & $\begin{array}{l}\text { Munculnya usaha- } \\
\text { usaha yang sama }\end{array}$ & 0,02 & 1 & 0,02 \\
\hline 15 & $\begin{array}{l}\text { Sinyal internet yang } \\
\text { tidak stabil }\end{array}$ & 0,02 & 1 & 0,02 \\
\hline 16 & $\begin{array}{l}\text { Pemalsuan bukti } \\
\text { transfer }\end{array}$ & 0,02 & 1 & 0,02 \\
\hline 17 & $\begin{array}{l}\text { Masuknya pasar luar } \\
\text { negeri }\end{array}$ & 0,03 & 2 & 0,06 \\
\hline
\end{tabular}


18

Daya beli konsumen terhadap online yang menurun

\begin{tabular}{ccc}
\hline Total & 0,5 & 0,68 \\
\hline
\end{tabular}

Sumber: data diolah peneliti (2018)

TABEL 1.5 RESUME EVALUASI FAKTOR INTERNAL

\begin{tabular}{lc}
\hline \multicolumn{2}{c}{ Resume Evaluasi Faktor Internal } \\
\hline Total Strenght & 2,43 \\
Total Weakness & 0,59 \\
\hline Total Evaluasi Faktor Internal & 3,02
\end{tabular}

Sumber: data diolah peneliti (2018)

TABEL 1.6 RESUME EVALUASI FAKTOR EKSTERNAL

\begin{tabular}{lc}
\hline \multicolumn{2}{c}{ Resume Evaluasi Faktor Eksternal } \\
\hline Total Opportunity & 2,5 \\
Total Threath & 0,68 \\
\hline Total Evaluasi Faktor eksternal & 3,18 \\
\hline
\end{tabular}

Sumber: data diolah peneliti (2018)

Faktor Eksternal yang paling mempengaruhi bisa dilihat dari Perkembangan Teknologi saat ini dan perkembangan Trend Hijab yang banyak mempengaruhi wanita Indonesia untuk berhijab karena itu pasar menuntut para pengusaha untuk terus berinovasi dalam mendesain kerudung.

\section{Lingkungan Internal dan Eksternal (IE)}

Nilai total skor rata-rata pada matriks IFE sebesar 3,02 sedangkan metriks EFE memperoleh total skor rata-rata sebesar 3,18. Hasil tersebut menempatkan Zavair scarves pada kuadran I. nilai skor rendah untuk matriks IFE dan nilai skor tinggi untuk matriks EFE. Pada posisi ini, dimungkinkan Zavair scarves melakukan strategi Market Penetration, Market Development, Product Development, Backward Integration, Forward Integration, Horizontal Intergration. Berikut bentuk matriks IE dari Zavair scarves dapat dilihat pada gambar 1.

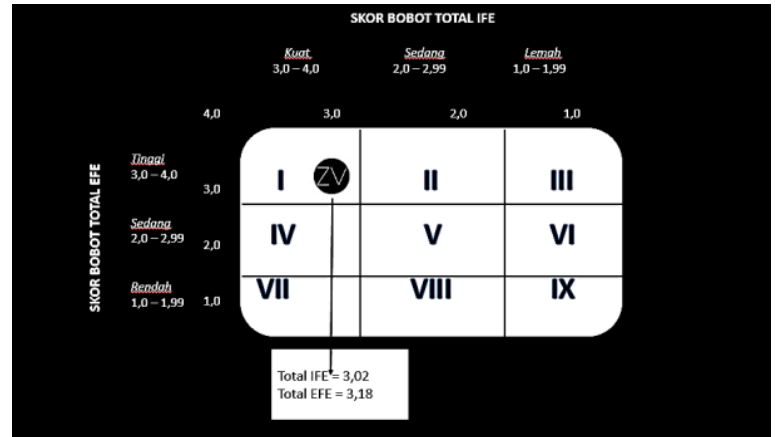

Sumber: data diolah peneliti (2018)

\section{GAMBAR 1.1 MATRIKS IE ZAVAIR}

Dari Gambar 1 dapat disimpulkan bahwa Zavair scraves berada pada kuadran (I) yaitu Grow \& build karena total skor yang didapatkan dari IFE sebesar 3,02 dan skor yang didapatkan dari EFE sebesar 3,18. Total skor dari kedua factor internal dan eksternal tergolong kategori Strong. Dengan demikian kondisi dari Zavair scarves ini terbilang cukup baik dan dapat terus berkembang kedepannya. Dengan bertumpu pada matrix IFE dan EFE diharapkan Zavair scarves dapat menutupi kelemahan yang ada dan focus pada kekuatan serta peluang yang dimiliki. Sehingga akan bisa menghadapi ancaman yang ada.

\section{Analisia SWOT dan TOWS}

Matrix SWOT merupakan langkah-langkah berdasarkan pengembangan dari matrix IE. Berbagai alternative strategi dapat dirumuskan berdasarkan pengembangan dari SWOT. Matrix TOWS yaitu Empat macam strategi utama yaitu strategi SO, ST, WO dan WT. Analisis ini menggunakan data yang diperoleh dari matrix IFE dan EFE diatas. Hasil analisa dilihat pada Tabel 7. Keunggulan dari penggunaan model ini adalah mudah memformulasikan strategi berdasarkan gabungan factor eksternal dan internal.

TABEL 1.7 MATRIKS ANALISIS SWOT DAN TOWS 


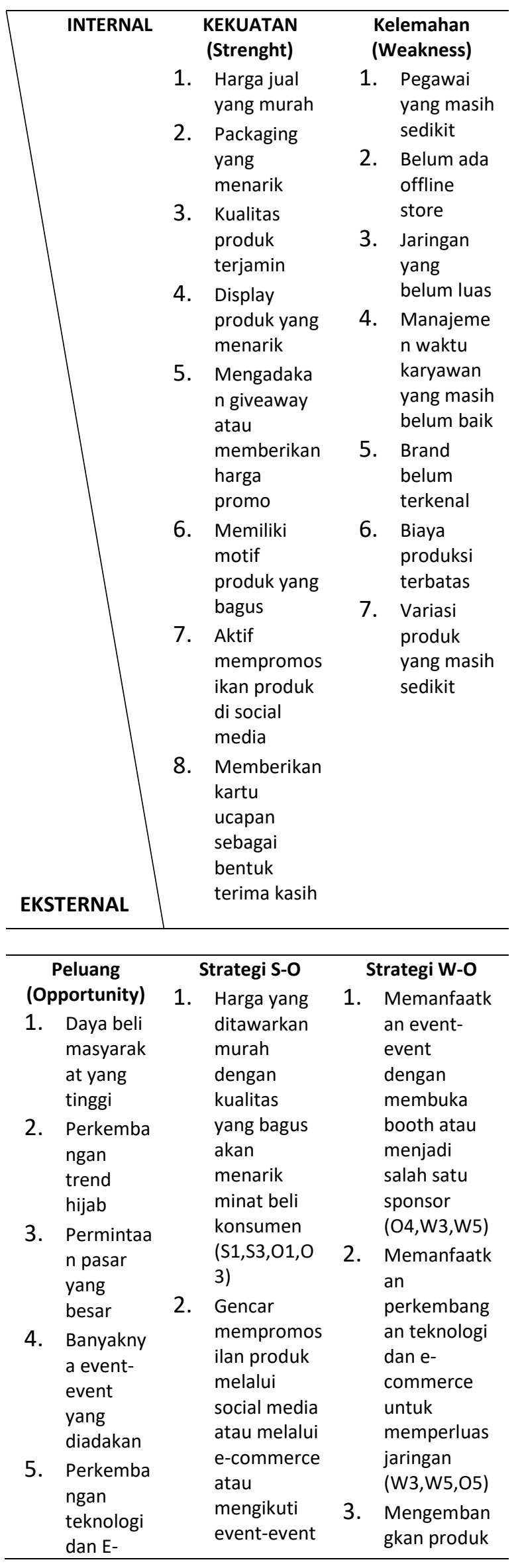

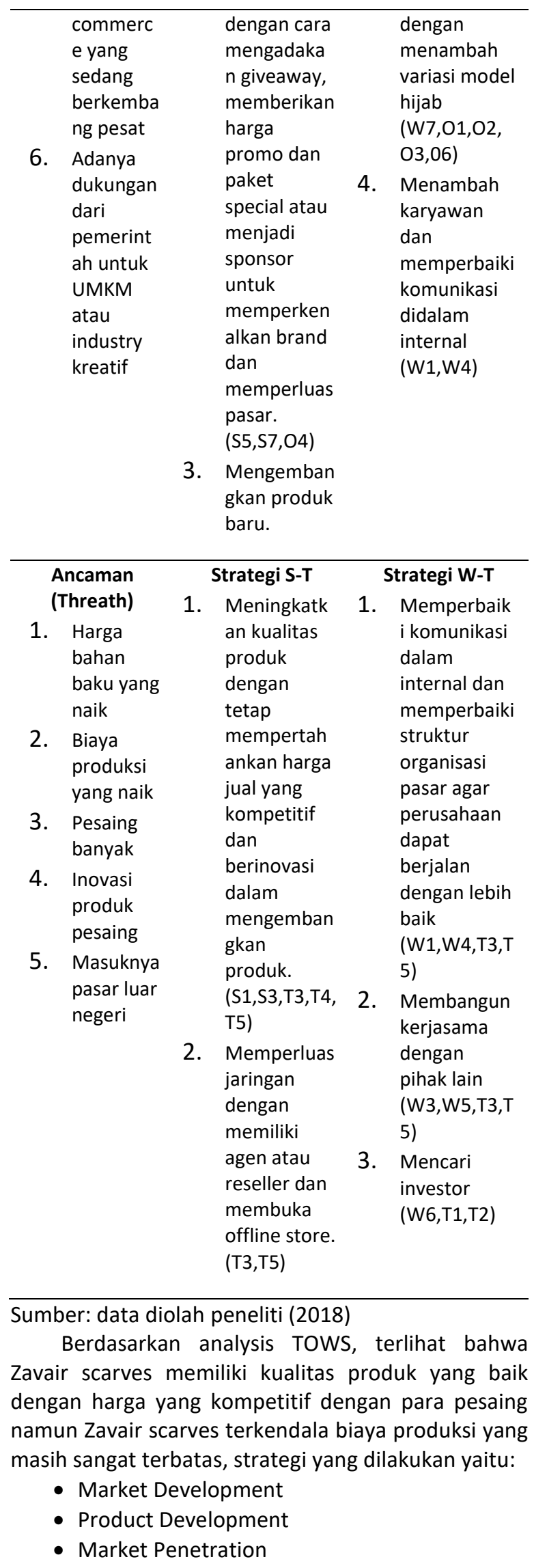




\section{BCG Matrix}

BCG Matrix merupakan metode yang digunakan dalam menyusun suatu perencanaan unit bisnis strategic dengan melakukan pengklasifikasian terhadap potensi keuntungan perusahaan (Kotler, 2009). BCG Matrix mempunyai 4 kuadran yaitu:

1. Question yaitu divisi dalam kuadran । memiliki posisi pangsa pasar relative yang rendah, tetapi mereka bersaing dalam industry yang bertumbuh pesat. Biasanya kebutuhan kas perusahaan ini tinggi dan pendapatan kasnya rendah. Bisnis ini disebut tanda Tanya karena organisasi harus memutuskan apakah akan memperkuat divisi ini dengan menjalankan strategi intensif (penetrasi pasar, pengembangan pasar atau pengembangan produk) atau menjualnya.

2. Star yaitu Bisnis di kuadran II (disebut juga Bintang) mewakili peluang jangka panjang terbaik untuk pertumbuhan dan profitabilitas bagi organisasi. Divisi dengan pangsa pasar relative yang tinggi dan tingkat pertumbuhan industry yang tinggi seharusnya menerima investasi yang besar untuk mempertahankan dan memperkuat posisi dominan mereka. Kategori ini adalah pemimpin pasar namun bukan berarti akan memberikan arus kas positif bagi perushaan, karena harus mengeluarkan banyak uang untuk memenangkan pasar dan mengantisipasi para pesaingnya. Integrasi ke depan, ke belakang, dan horizontal, penetrasi pasar, pengembangan pasar, pengembangan produk dan joint venture merupakan strategi yang sesuai untuk dipertimbangkan divisi ini.

3. Cash Cow yaitu divisi yang berposisi di kuadran III memiliki pangsa pasar relative yang tinggi tetapi bersaing dalam industry yang pertumbuhannya lambat. Disebut sapi perah karena menghasilkan kas lebih dari yang dibutuhkan, mereka seringkali diperah untuk membiayai sector usaha yang lain. Banyak sapi perah saat ini adalah bintang di masa lalu, divisi sapl perah harus dikelola untuk mempertahankan posisi kuatnya selama mungkin. Pengembangan produk atau diversifikasi konsentrik dapat menjadi strategi yang menarik untuk sapi perah yang kuat. Tetapi, ketika divisi sapi perah menjadi lemah, retrenchment atau divestasi lebih sesuai untuk diterapkan.

4. Dog yaitu divisi kuadran IV dari organisasi memiliki pangsa pasar relative yang rendah dan bersaing dalam industry yang pertumbuhannya rendah atau tidak tumbuh. Mereka adalah anjing dalam protofolio perusahaan. Karena posisi internal dan eksternalnya lemah, bisnis ini seringkai dilikuidasi, divestasi atau dipangkas dengan retrenchment. Ketika sebuah divisi menjadi anjing, retrenchment dapat menjadi strategi yang terbaik.

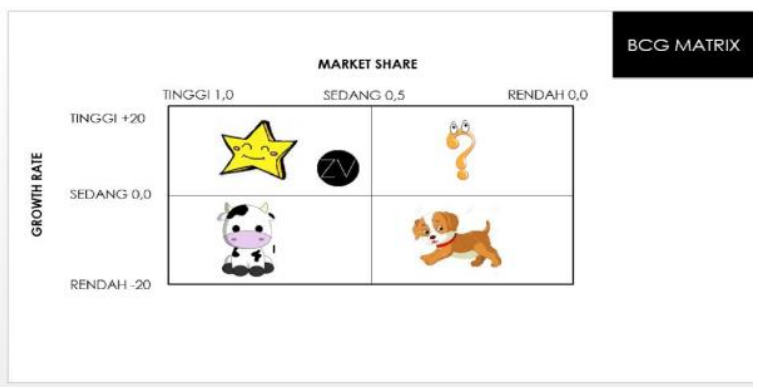

Sumber: data diolah peneliti (2018)

\section{GAMBAR 1.2 BCG MATRIX}

Melalui Analisis BCG Matrix, Zavair scarves berada pada kuadran perusahaan STAR (gambar 15). Pada kuadran ini Zavair scarves dapat menerapkan strategi terdiri dari:

1. Forward integration (integrasi ke depan) yaitu memiliki atau meningkatkan kendali atas distributor atau pengecer.

2. Backward integration (integrasi ke belakang) yaitu mencoba memiliki atau meningkatkan kendali atas perusahaan pemasok.

3. Horizontal integration (integrasi horizontal) yaitu mencoba memiliki atau meningkatkan kendali atas para pesaing.

4. Market penetration (penetrasi pasar) yaitu mencari pangsa pasar yang lebih besar untuk produk atau jasa yang sudah ada sekarang melalui usaha pemasaran yang lebih gencar.

5. Market development (pengembangan pasar) yaitu memperkenalkan produk atau jasa yang sudah ada ke wilayah geografi baru.

6. Product development (pengembangan produk) yaitu mencoba meningkatkan penjualan dengan memperbaiki produk atau jasa yang sudah ada atau mengembangkan yang baru.

7. Joint venture (usaha bersama)

\section{KESIMPULAN}

Hasil dari perhitungan pada factor internal dan eksternal menunjukkan posisi Zavair scarves saat ini berada pada kuadran I dengan nilai sebesar $(3,02$; 
3,18). Serta analisis SWOT dan TOWS menghasilkan sepuluh alternatif strategi dengan prioritas strategi yaitu market penetration, market development dan product development. Berdasarkan analisis BCG Matrix menghasilkan 7 alternatif strategi yaitu forward integration, backward integration, horizontal integration, market penetration, market development, product development dan joint venture. Berdasarkan analisis dari SWOT, TOWS dan BCG Matrix, bahwa market penetration, market development dan product development merupakan strategi yang paling penting digunakan untuk memajukan Zavair scarves.

\section{REKOMENDASI}

Dengan memakai Analisis SWOT dan BCG Matriks, Zavair scraves dapat mengetahui posisi keberadaan perusahaan saat ini, penelitian ini menunjukkan bahwa dengan analisis yang tepat sebuah perusahaan dapat menemukan solusi dalam mengembangkan bisnisnya. Pengembangan penelitian ini dapat dilakukan oleh peneliti lain dengan memakai metode yang sama ditambah dengan metode terbaru lainnya. Agar sebuah perusahaan mendapatkan model bisnis yang tepat untuk perkembangan dan kesuksesan perusahaan di masa depan.

\section{DAFTAR PUSTAKA}

Alexander Osterwalder and Yves Pigneur. (2018). Business Model Generation. Jakarta: PT. Elex Media Komputindo

Barusman M, Y, S \& Gunardi, S (2014). ANALISIS PORTOPOLIO PRODUK PADA PT. ASURANSI UMUM BUMIPUTERA 1967 CABANG LAMPUNG MENGGUNAKAN MATRIK BOSTON CONSULTING GROUP (BCG). Journal Manajemen dan Bisnis, Vol. 4 No. 2. $141-161$

Buchari, Alma (2009). KEWIRAUSAHAAN. Bandung. Alfabeta

David, F. R. (2006). Manajemen Strategis, Konsep. Edisi 10 (terjemahan). Buku 1. Jakarta: Salemba Empat.

Gassman, O., Frankerberger, C \& Csik, M. (2016). Bisnis Model Navigator: 55 model bisnis yang akan mengubah bisnis anda. Jakarta: PT. Elex Media Komputindo

Guntara, S, R. Yogaswara, B. Aurachman, R (2017). STRATEGI TRANSFORMASI GREENERATION INDONESIA MENUJU PERUSAHAAN RAMAH LINGKUNGAN YANG UNGGUL DENGAN PENDEKATAN MATRIKS BOSTON CONSULTING GROUP. E-Proceeding of, Vol 4, No 3, ISSN 23559365.
Hardiyansyah A, Ikhwana A, Kurniawati R (2015). ANALISIS STRATEGI PEMASARAN USAHA MIE BASAH. Jurnal kalibrasi Sekolah Tinggi Teknologi Garut, ISSN: 2302-7320 Vol. 13 No. 1.

Isnandar, F, R. Firdaus, M. Maulana, A (2016). STARTEGI PENINGKATAN ASET PT. BPR SYARIAH HARTA INSAN KARIMAH (HIK) CILEDUG. Jurnal Aplikasi Bisnis dan Manajemen, Vol. 2 No. 1, EISSN: 2460-7819. Nomor DOI: 10.17358/JABM.2.1.12

Kotler, P. (2009). Manajemen Pemasaran, Jakarta: Penerbit Erlangga

Kuntjoroardi, W \& Safitri, N. (2009). ANALISIS STRATEGI BERSAING DALAM PERSAINGAN USAHA PENERBANGAN KOMERSIAL. Bisnis \& Birokrasi, Jurnal IImu Administrasi \& Organisasi 45-52, Vol 16, No 1, ISSN 0854-3844.

Maulana, A. Sukamdani, N, B. Sulistyadi, K (2016). STRATEGI PENGEMBANGAN DESTINASI KEPULAUAN SERIBU BERDASARKAN PENDEKATAN BOSNTIN CONSULTING GROUP (BCG).

Nurhasanah, N. (2006). PERUMUSAN STRATEGI PEMASARAN MELALUI PENENTUAN PRIORITAS TRAPEZODIAL FUZZY NUMBER (Studi Kasus Industri Minuman Tradisional). Jurnal Teknik Industri, Vol. 8, No. 2, 131-140.

Poniran (2013). STRATEGI THE BOSTON CONSULTING GROUP UNTUK MEMASTIKAN KESINAMBUNGAN PRODUK PT GUDANG GARAM Tbk KEDIRI. Wacana Vol 16, No 1, ISSN 1411-0199.

Savitri D.A, Sumarwan U, Kurniawan B.P Y. (2014). DAYA SAING DAN MODEL PEMASARAN SENTRA INDUSTRI USAHA KERAJINAN SANGKAR BURUNG PERKUTUT. Jurnal Manajemen Agribisnis, Vol. 11 No. 1.

Sarjono, H \& Kuncoro, E, A. (2013). ANALISIS MATRIKS BOSTON CONSULTING GROUP (BCG) UNTUK MEMENANGKAN STRATEGI ORGANISASI (Studi Kasus Perguruan Tinggi di Kopertis Wilayah III-DKI Jakarta). Binus Business Review, Vol 4, No 1, 414422.

Suranto. (2003). PENENTUAN POSISI DAN STRATEGI PEMASARAN PADA PERUSAHAAN FIRMA SIDODADI. Jurnal Ilmiah Teknik Industri, Vol. 01, No. 03, 130-139.

Suryana (2017). KEWIRAUSAHAAN (Kiat dan Proses menuju Sukses). Jakarta. Salemba Empat

Torlak, NG and Sanal M. (2007). David's Strategy Formulation Framework in Action: The Example of Turkish Airline on Domestic Air Transportation. Istanbul Ticaret Universitesi Fen Bilimleri Dergisi Yul: 6 Sayi:12 Guz 2007/2 s.81-114 
Winardi, M, A. (2014). STRATEGI OPERASIONAL BISNIS KONSULTAN DI JAKARTA UNTUK MERAIH PELUANG YANG LEBIH BAIK. Jurnal MIX, Vol IV, No 2, 135-150. 